Research, Society and Development, v. 9, n. 8, e317985569, 2020

(CC BY 4.0) | ISSN 2525-3409 | DOI: http://dx.doi.org/10.33448/rsd-v9i8.5569

\title{
A Enfermagem na prevenção da flebite ocasionada por medicamentos
}

Nurse's activities in the prevention of phlebitis caused by medicines Enfermería en la prevención de flebitis causada por medicamentos

Recebido: 12/06/2020 | Revisado: 13/06/2020 | Aceito: 24/06/2020 | Publicado: 06/07/2020

Marlise dos Santos Borges

ORCID: https://orcid.org/0000-0002-7571-2323

Universidade Estácio de Sá, Brasil

E-mail:marmundial@hotmail.com

Jorge Luiz Lima da Silva

ORCID: https://orcid.org/0000-0002-2370-6343

Universidade Federal Fluminense, Brasil

E-mail: jorgeluizlima@gmail.com

Giulia Lemos de Almeida

ORCID: https://orcid.org/0000-0003-1783-3298

Universidade Federal Fluminense, Brasil

E-mail: giulialemos@id.uff.br

Lia Cristina Galvão dos Santos

ORCID: https://orcid.org/0000-0001-6728-0906

Hospital Geral de Bonsucesso, Brasil

E-mail: galvaoconsult@gmail.com

Lunna Machado Soares

ORCID: https://orcid.org/0000-0001-7737-202X

Universidade Federal Fluminense, Brasil

E-mail: lunna_machado@hotmail.com

Vittória Thiengo Oliveira Moreira Rego

ORCID: https://orcid.org/0000-0003-1897-5976

Universidade Federal Fluminense, Brasil

E-mail: vittoriathiengo@gmail.com

João Victor Lima da Silva

ORCID: https://orcid.org/0000-0002-5561-0303

Universidade Federal Fluminense, Brasil

E-mail: limajoao@id.uff.br 


\title{
Resumo
}

Objetivo: descrever cuidados da equipe de enfermagem na prevenção e tratamento das complicações da punção venosa periférica em pacientes internados na UTI. Material e Método: metodologia utilizada foi de natureza descritiva, realizada através de revisão bibliográfica publicadas no período de 2008 a 2019, cujo levantamento foi realizado em virtualmente na Biblioteca Virtual de Saúde (BVS), nas bases: Medline e Lilacs. Resultados: a flebite pode ser evitada pela realização de técnica asséptica durante a inserção do dispositivo venoso e adoção de material adequado e de tamanho apropriado para o calibre da veia, de preferência de pequeno calibre, que seja flexível com alta resistência a dobras, integridade estrutural, fácil inserção, baixa trombogenicidade e aderência bacteriana. Conclusão: foi possível identificar que as condutas são muito semelhantes nos diferentes serviços e que a maioria dos cuidados são procedimentos comuns de enfermagem e que possuem eficácia comprovada por meio de estudos científicos.

Palavras-chave: Papel do profissional de Enfermagem; Flebite; Cateterismo.

\begin{abstract}
Objective: describe the nurse`s team care in the prevention and treatment of the complications in peripheric venous puncture in patients in the ICU. Method: the methodology used was descriptive, carried out through a bibliographic review published in the period from 2008 to 2019, whose survey was performed in a virtual environment in the Virtual Health Library (VHL), on the bases: Medline and Lilacs. Results: phlebitis can be prevented by performing aseptic technique during insertion of the venous device and adopting suitable material of appropriate size for vein caliber, preferably of small caliber, which is flexible with high resistance to bending, structural integrity, easy insertion, low thrombogenicity and bacterial adherence. Conclusion: it was possible to identify that the ducts are very similar in different services and that most care are common nursing procedures and have proven efficacy through scientific studies.
\end{abstract}

Keywords: Nurse's role; Phlebitis; Catheterization.

\section{Resumen}

Objetivo: describir la atención del equipo de enfermería en la prevención y el tratamiento de complicaciones de la venopunción periférica en pacientes ingresados en la UCI. Método: la metodología utilizada fue de carácter descriptivo, realizada mediante revisión bibliográfica publicada en el período 2008 a 2019, cuya encuesta se realizó en un entorno virtual en la 
Biblioteca Virtual en Salud (BVS), en las bases: Medline y Lilacs. Resultados: la flebitis se puede evitar realizando una técnica aséptica durante la inserción del dispositivo venoso y adoptando un material adecuado del tamaño de la vena, preferiblemente de pequeño calibre, que sea flexible con alta resistencia a los pliegues, integridad estructural, fácil inserción, baja trombogenicidad y adherencia bacteriana. Conclusión: con base en los resultados de esta investigación, fue posible identificar que las conductas son muy similares en los diferentes servicios y que la mayoría de los cuidados son procedimientos de enfermería comunes y que han demostrado su eficacia a través de estudios científicos.

Palabras clave: Rol de la Enfermera; Flebitis; Cateterismo.

\section{Introdução}

No ambiente hospitalar, a segurança do paciente tem gerado debates em âmbito mundial, e recebido várias interpretações, dentre as quais, a de que segurança consiste na redução do risco e danos desnecessários associados à assistência em saúde até um mínimo aceitável (Lourenço \& Kakehashi, 2013).

O mínimo aceitável se refere àquilo que é viável, diante do conhecimento atual, dos recursos disponíveis e do contexto em que a assistência foi realizada frente ao risco de não tratamento, ou outro tipo de tratamento. Entre os recursos disponíveis, o uso de medicamentos é um dos mais empregados, no entanto, eventos adversos e erros relacionados a medicamentos são frequentes (Nomi, 2016).

A punção venosa periférica é um procedimento que consiste no acesso à corrente sanguínea, através de dispositivos adequados, adjuntos de seleção criteriosa do local da punção e de eficiente técnica de penetração da veia. A cateterização periférica é a primeira escolha em uma situação de emergência, pela facilidade técnica, variedade de calibres e rapidez da punção (Waitt, Waitt \& Pirmohamed, 2014).

A canulação periférica é indicada para terapias infusionais de curta duração, ou seja, até sete dias, para infusões de medicamentos e/ou quimioterápicos não vesicantes, nutrição parenteral, coleta de exames sanguíneos e reposição de hemoderivados (Oliveira, Bezerra \& Pereira, 2008). A cateterização intravenosa periférica é o procedimento invasivo mais comum realizado entre pacientes hospitalizados. Entretanto, não está livre de riscos (Webster et al. 2010).

Com o avanço no desenvolvimento de tratamentos e drogas, a terapia intravenosa vem se tornando cada vez mais complexa, aumentando os riscos de complicações para os pacientes. 
Assim, conhecê-las, buscar informações sobre práticas seguras, estar alerta aos seus sinais e sintomas para preveni-las e tratá-las deve ser uma prioridade da enfermagem (Torres, Andrade \& Santos, 2015; Hamilton, 2008).

A flebite é uma das complicações mais frequentes do uso de cateteres venosos periféricos (CVP). Caracterizando-se por uma inflamação aguda da veia, causando edema, dor, desconforto, eritema ao redor da punção e um "cordão" palpável ao longo do trajeto da veia (Phillips, 2011). A incidência de flebite é de 10,5\%, ou seja, o dobro dos 5\% esperado pelo Intravenous Nurses Society (Ferreira, Pedreira \& Diccini, 2009; Intravenous Nurses Society, 2012). Além desse aspecto, os pesquisadores constataram outro fator preocupante, um período de permanência de 2 a 216 horas do acesso venoso, quando o recomendado seria o período de manutenção entre 72 a 96 horas, conforme Center for Diseases Control and Prevention (Centers for disease control and prevention, 2015).

Portanto, no intuito de evitarem-se complicações se fazem extremamente necessários que os profissionais de enfermagem, tenham conhecimento sobre a anatomia, fisiologia, microbiologia e farmacologia, atualizando-se constantemente por meio de atividades educativas, obtendo-se dessa forma, a qualificação de toda a equipe (Torres, Andrade \& Santos, 2015).

Mediante ao exposto, este estudo tem como objetivo descrever cuidados da equipe de enfermagem na prevenção e tratamento das complicações da punção venosa periférica em pacientes internados na UTI.

\section{Metodologia}

A pesquisa de natureza descritiva foi realizada por meio de revisão bibliográfica sistematizada e baseada em obras secundárias que abordavam o tema em questão, publicadas no período de 2008 a 2019. A coleta do material foi realizada no período de outubro de 2018 a fevereiro de 2019.

O levantamento foi realizado em ambiente virtual na Biblioteca Virtual de Saúde (BVS), nas bases: Medline e Lilacs e em uma busca livre de textos completos incluídos, nos resultados com os seguintes descritores: "atuação do enfermeiro", "prevenção à flebite", "flebite medicamentosa". Tais termos foram utilizados de forma conjunta e isolados. As obras idênticas, repetidas em bases diferentes, foram eliminadas, considerou-se seu primeiro registro.

Foram selecionados para este estudo somente artigos que, na leitura demonstrasse conteúdos com o processo da assistência de enfermagem de forma integral e singular a 
(CC BY 4.0) | ISSN 2525-3409 | DOI: http://dx.doi.org/10.33448/rsd-v9i8.5569

parturiente, utilizando como fonte periódica da área de enfermagem publicada no Brasil, que estavam disponíveis nos locais selecionados para a coleta, descritos no Quadro 1. Primeiramente, as obras foram armazenadas em computador, para que em seguida fosse realizada uma pré-seleção de acordo com a leitura dos resumos. Nessa fase, buscou-se a relação entre o conteúdo, título, resumo, e se atendiam ao objeto do presente estudo.

$\mathrm{Na}$ fase de seleção, as obras foram lidas na íntegra, com atenção especial para os resultados e conclusão das obras, os trabalhos que não apresentavam qualquer relação com o caráter assistencial foram excluídos. Realizada a triagem das obras foram obtidos nove artigos.

Ao utilizar os termos de busca "atuação do enfermeiro", "prevenção à flebite", "flebite medicamentosa" foram encontrados 56 artigos, quatro se adequavam aos parâmetros estabelecidos, foram descartados 52 artigos. Em busca livre de textos completos atendendo aos critérios científicos na internet, foram selecionados três artigos.

Após a construção das fases da elaboração do estudo, percebeu-se que somente os estudos encontrados em meio virtual não subsidiaram o aspecto conceitual básico, visto que abordavam a assistência de forma generalizada, por isso além do material encontrado na BVS foram utilizados livros de biblioteca física, onde foram selecionadas as obras mais recentes e com relação com o caráter da assistência de enfermagem. Depois das etapas descritas acima, foram construídos nos resultados o Quadro 1, com síntese das obras. 
Quadro 1. Distribuição dos artigos de acordo com os periódicos selecionados em ambiente da BVS no período de 2008 a 2019.

\begin{tabular}{|l|c|c|c|c|c|c|c|c|c|c|}
\hline \multicolumn{1}{|c|}{ PERIÓDICOS } & \multicolumn{9}{|c|}{ Ano de publicação } \\
\hline & 2008 & 2009 & 2010 & 2011 & 2012 & 2013 & 2014 & 2015 & 2016 & Total* \\
\hline $\begin{array}{l}\text { Rev. Bras. } \\
\text { Enferm. }\end{array}$ & - & 1 & - & - & 1 & - & - & 1 & 1 & 4 \\
\hline $\begin{array}{l}\text { Rev. Saúde } \\
\text { Public. }\end{array}$ & 1 & - & - & - & - & - & - & - & - & 1 \\
\hline $\begin{array}{l}\text { Rev. Esc. Enferm. } \\
\text { USP Gaúcha. }\end{array}$ & - & - & - & - & - & 1 & - & - & - & 1 \\
\hline $\begin{array}{l}\text { R. } \\
\text { Enferm. }\end{array}$ & - & - & - & - & - & - & - & - & 1 \\
\hline $\begin{array}{l}\text { Rev. Enferm. } \\
\text { UFPE On Line }\end{array}$ & 1 & - & - & - & - & - & - & - & 1 & 2 \\
\hline \begin{tabular}{l} 
Total \\
\hline
\end{tabular} & 3 & 1 & 0 & 0 & 1 & 1 & 0 & 1 & 2 & 9 \\
\hline
\end{tabular}

*As obras encontradas nos anos de 2017 a 2019 não contemplaram objeto de estudo.

Fonte: os autores (2020).

A primeira etapa consistiu no capturar dos artigos científicos pela Biblioteca Virtual em Saúde (BVS), nas bases de dados: Medline e Lilacs. Os textos encontrados passaram por um processo de refinamento, ocorrendo da seguinte forma: primeiro a seleção dos Descritores em Ciências da Saúde (DeSC): "atuação do enfermeiro", "prevenção à flebite", "flebite medicamentosa". Em seguida, busca dos artigos, através da combinação dos descritores: "atuação do enfermeiro + prevenção à flebite"; "atuação do enfermeiro + flebite medicamentosa"; "prevenção à flebite + flebite medicamentosa". Foram excluídos os artigos de periódicos não nacionais e que não apresentavam versão em texto completo. Foi realizada coleta do período de 2008 a 2019.

\section{Resultados}

Foi realizada classificação dos artigos científicos levantados e organização dos dados. Nesse item, com o objetivo de possibilitar ao leitor uma melhor compreensão dos artigos identificados pela coleta em ambiente virtual e físico, foi construído Quadro 2, conforme pode 
ser evidenciado abaixo.

Quadro 2. Publicações selecionadas para discussão, capturadas nas bases Medline e Lilacs, publicadas nos últimos anos.

\begin{tabular}{|c|c|c|c|c|}
\hline $\begin{array}{c}\text { Autor; } \\
\text { Ano; País. }\end{array}$ & $\begin{array}{c}\text { Objetivo da } \\
\text { pesquisa }\end{array}$ & $\begin{array}{c}\text { Método; } \\
\text { Tamanho da } \\
\text { amostra; } \\
\text { Tipo de estudo }\end{array}$ & $\begin{array}{l}\text { Principais } \\
\text { achados }\end{array}$ & $\begin{array}{c}\text { Conclusão do } \\
\text { artigo }\end{array}$ \\
\hline $\begin{array}{l}\text { Barria, } \\
\text { Santande - } \\
2008, \\
\text { Brasil. }\end{array}$ & $\begin{array}{l}\text { Identificar as } \\
\text { veias } \\
\text { periféricas de } \\
\text { escolha, para a } \\
\text { punção } \\
\text { venosa, no } \\
\text { recém-nascido } \\
\text { e descrever os } \\
\text { critérios } \\
\text { adotados pela } \\
\text { equipe de } \\
\text { enfermagem } \\
\text { na escolha } \\
\text { desses vasos. }\end{array}$ & $\begin{array}{l}\text { O cenário foi uma } \\
\text { Unidade de Terapia } \\
\text { Intensiva Neonatal } \\
\text { do Rio de Janeiro, } \\
\text { Brasil. Foram } \\
\text { entrevistados dez } \\
\text { profissionais } \\
\text { enfermagem de } \\
\text { maio a junho de } \\
\text { 2007. }\end{array}$ & $\begin{array}{l}\text { As veias do arco } \\
\text { dorsal da mão } \\
\text { foram as de } \\
\text { primeira escolha e } \\
\text { as epicranianas as } \\
\text { de última escolha. } \\
\text { Os critérios de } \\
\text { escolha foram } \\
\text { visualização, } \\
\text { facilidade, } \\
\text { durabilidade e } \\
\text { fármaco infundido. }\end{array}$ & $\begin{array}{l}\text { As dificuldades } \\
\text { enfrentadas para a } \\
\text { realização de } \\
\text { terapia intravenosa } \\
\text { no recém-nascido } \\
\text { foram o desgaste } \\
\text { da rede venosa e a } \\
\text { dor advinda das } \\
\text { múltiplas punções. }\end{array}$ \\
\hline $\begin{array}{l}\text { Carvalho, } \\
\text { Cassiani - } \\
\text { 2012, } \\
\text { Brasil. }\end{array}$ & $\begin{array}{l}\text { Analisar as } \\
\text { consequências } \\
\text { de erros } \\
\text { ocorridos para } \\
\text { os pacientes e } \\
\text { profissionais } \\
\text { de } \\
\text { enfermagem } \\
\text { com base em } \\
\text { relatos de } \\
\text { erros. }\end{array}$ & $\begin{array}{lr}\text { O estudo foi } \\
\text { realizado em um } \\
\text { hospital do estado } \\
\text { de São Paulo, em } \\
2010 \text {. Os dados } \\
\text { foram extraídos das } \\
\text { entrevistas } \\
\text { realizadas com } 7 \\
\text { enfermeiros, } \\
\text { técnico e } \\
\text { auxiliares } \\
\text { enfermagem. }\end{array}$ & $\begin{array}{l}\mathrm{Na} \text { análise foram } \\
\text { identificadas } \\
\text { consequências do } \\
\text { erro para o paciente } \\
\text { e para o profissional } \\
\text { de enfermagem. }\end{array}$ & $\begin{array}{lr}\text { Conclui-se } & \text { a } \\
\text { necessidade de } & \text { se } \\
\text { notificarem } & \text { os } \\
\text { erros na medicação } & \\
\text { para que se } & \text { verifiquem suas } \\
\text { causas, índices } & \text { e } \\
\text { consequências por } & \text { parte } \\
\text { instituições } & \\
\text { hospitalares. }\end{array}$ \\
\hline $\begin{array}{l}\text { Écheli, } \\
\text { Busato- } \\
2016 \text {, }\end{array}$ & $\begin{array}{l}\text { Diagnosticar e } \\
\text { padronizar de } \\
\text { forma } \\
\text { adequada } \\
\text { tratamento }\end{array}$ & $\begin{array}{lr}\text { Com base na } \\
\text { metodologia } \\
\text { coleta de dados } \\
\text { forma } \\
\text { questionário, }\end{array}$ & $\begin{array}{l}\text { Ficou constatado } \\
\text { que não existe } \\
\text { protocolo para tal e }\end{array}$ & $\begin{array}{lr}\text { Porém, isto não } \\
\text { impede que o } \\
\text { tratamento } \\
\text { realizado } \\
\text { eficiência }\end{array}$ \\
\hline
\end{tabular}




\begin{tabular}{|c|c|c|c|c|}
\hline Brasil. & $\begin{array}{l}\text { tópico da } \\
\text { úlcera de } \\
\text { estase venosa, } \\
\text { em todas as } \\
\text { suas fases. }\end{array}$ & $\begin{array}{l}\text { realizado por } \\
\text { enfermeira do } \\
\text { Programa Saúde da } \\
\text { Família em Castro - } \\
\text { Paraná, no mês de } \\
\text { maio (2014). }\end{array}$ & $\begin{array}{l}\text { muita vez há falta } \\
\text { de produtos. }\end{array}$ & $\begin{array}{lr}\text { utilizando-se } & \text { o } \\
\text { disponível } & \mathrm{e} \\
\text { adquirindo alguns } \\
\text { produtos } \\
\text { essenciais. }\end{array}$ \\
\hline $\begin{array}{l}\text { Grivicich, } \\
\text { Regner, } \\
\text { Rocha- } \\
2008, \\
\text { Brasil. }\end{array}$ & $\begin{array}{l}\text { Revisar o } \\
\text { processo da } \\
\text { apoptose, seus } \\
\text { mecanismos } \\
\text { celulares, sua } \\
\text { regulação por } \\
\text { fatores } \\
\text { externos e sua } \\
\text { participação } \\
\text { em várias } \\
\text { doenças } \\
\text { hepatobiliares. }\end{array}$ & $\begin{array}{l}\text { Pesquisa } \\
\text { bibliográfica. }\end{array}$ & $\begin{array}{lr}\text { O conhecimento } \\
\text { dos mecanismos } \\
\text { celulares da } \\
\text { apoptose, bem } \\
\text { como seus } \\
\text { desequilíbrios } \\
\text { durante distúrbios } \\
\text { fisiopatológicos } \\
\text { possibilitam melhor } \\
\text { compreensão das } \\
\text { doenças que afetam } \\
\text { o fígado e vias } \\
\text { biliares. }\end{array}$ & $\begin{array}{lr}\text { A } & \text { inibição } \\
\text { farmacológica da } \\
\text { apoptose ou sua } \\
\text { indução podem } \\
\text { oferecer grandes } \\
\text { perspectivas no } \\
\text { tratamento } \\
\text { doenças nas quais } \\
\text { ocorra } \\
\text { desequilíbrio no } \\
\text { processo natural de } \\
\text { morte celular. }\end{array}$ \\
\hline $\begin{array}{l}\text { Lourenço, } \\
\text { kakehashi- } \\
2013, \\
\text { Brasil. }\end{array}$ & $\begin{array}{l}\text { Avaliar a } \\
\text { implantação } \\
\text { do cateter } \\
\text { venoso central } \\
\text { de inserção } \\
\text { periférica em } \\
\text { neonatologia. }\end{array}$ & $\begin{array}{l}\text { O presente trabalho } \\
\text { versa sobre os } \\
\text { resultados obtidos } \\
\text { com a inserção de } \\
135 \text { cateteres em } \\
\text { neonatos, numa } \\
\text { unidade de Terapia } \\
\text { Intensiva Neonatal } \\
\text { na cidade de Santos } \\
\text { - SP, no período de } \\
\text { junho de } 2010 \text { a } \\
\text { dezembro de } 2012 .\end{array}$ & $\begin{array}{lr}\text { Os } & \text { resultados } \\
\text { mostraram } & \text { uma } \\
\text { média } & \text { de } \\
\text { permanência } & \text { dos } \\
\text { cateteres de } & 20 \text { dias. }\end{array}$ & $\begin{array}{l}\text { Os cateteres } \\
\text { venosos de } \\
\text { inserção periférica } \\
\text { demostram ser uma } \\
\text { alternativa segura e } \\
\text { ideal de utilização } \\
\text { em recém- } \\
\text { nascidos, quando } \\
\text { comparados aos } \\
\text { dados da literatura. }\end{array}$ \\
\hline $\begin{array}{l}\text { Nomi - } \\
\text { 2016, } \\
\text { Brasil. }\end{array}$ & $\begin{array}{ll}\text { Verificar } & \text { a } \\
\text { incidência de } \\
\text { infecção da } \\
\text { corrente } \\
\text { sanguínea } \\
\text { relacionada ao } \\
\text { cateter venoso } \\
\text { central e de } \\
\text { hemodiálise. }\end{array}$ & $\begin{array}{l}\text { Trata-se de um } \\
\text { estudo descritivo } \\
\text { exploratório com } \\
\text { abordagem } \\
\text { quantitativa, } \\
\text { desenvolvido na } \\
\text { unidade de terapia } \\
\text { intensiva } \\
\text { Hospital do } \\
\text { Universitário Pedro } \\
\text { Ernesto/UERJ. }\end{array}$ & $\begin{array}{lr}\text { Foi } & \text { possível } \\
\text { verificar } & \text { a } \\
\text { incidência } & \text { da } \\
\text { infecção } \\
\text { relacionada } \\
\text { corrente sanguínea } \\
\text { dos acessos } \\
\text { venosos centrais e } \\
\text { de hemodiálise, de } \\
\begin{array}{ll}12 \% \text { e } 14 \% \\
\text { respectivamente, }\end{array}\end{array}$ & $\begin{array}{l}\text { Conclua-se que a } \\
\text { vigilância e o } \\
\text { trabalho realizados } \\
\text { na unidade com o } \\
\text { uso de indicadores } \\
\text { de qualidade } \\
\text { representam uma } \\
\text { importante } \\
\text { ferramenta que } \\
\text { possibilita } \\
\text { descrever }\end{array}$ \\
\hline
\end{tabular}




\begin{tabular}{|c|c|c|c|c|}
\hline & & $\begin{array}{l}\text { Foram } \\
\text { considerados todos } \\
\text { os sujeitos } \\
\text { admitidos/internad } \\
\text { os no CTI Geral, no } \\
\text { período entre os } \\
\text { meses de julho e } \\
\text { setembro de } 2010 .\end{array}$ & $\begin{array}{l}\text { tendo como } \\
\text { principal micro- } \\
\text { organismo presente } \\
\text { nas culturas de } \\
\text { ponta de cateter o } \\
\text { Acinetobacter sp.. }\end{array}$ & $\begin{array}{l}\text { realidade } \\
\text { situação, apontar } \\
\text { os problemas e, } \\
\text { assim, planejar as } \\
\text { ações frente aos } \\
\text { fatores que possam } \\
\text { desencadear riscos } \\
\text { ao paciente. }\end{array}$ \\
\hline $\begin{array}{l}\text { Oliveira, } \\
\text { Bezerra, } \\
\text { Pereira - } \\
2008, \\
\text { Brasil. }\end{array}$ & $\begin{array}{l}\text { Descrever a } \\
\text { assistência de } \\
\text { enfermagem } \\
\text { vivenciada } \\
\text { pela } \\
\text { enfermeira no } \\
\text { cateterismo } \\
\text { venoso } \\
\text { periférico. }\end{array}$ & $\begin{array}{l}\text { Pesquisa de Campo } \\
\text { em Unidade de } \\
\text { Terapia Intensiva } \\
\text { Pediátrica, } \\
\text { Fortaleza-CE. }\end{array}$ & 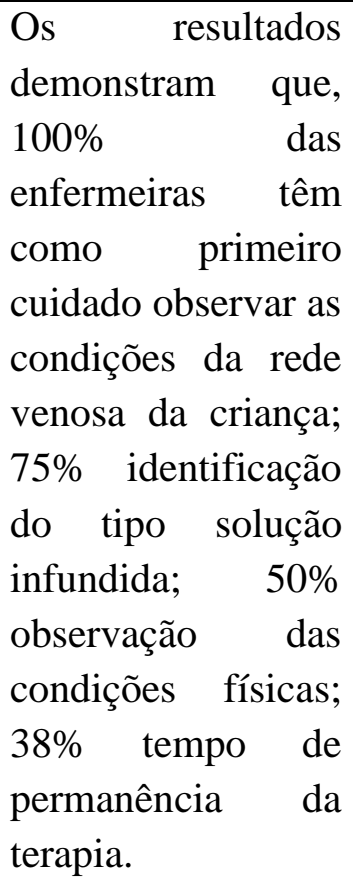 & $\begin{array}{l}\text { A enfermeira } \\
\text { deverá repensar a } \\
\text { prática } \\
\text { profissional, } \\
\text { procurando a } \\
\text { sedimentação dos } \\
\text { papéis de cuidar e } \\
\text { gerenciar como } \\
\text { não dissociáveis do } \\
\text { trabalho } \\
\text { enfermagem. }\end{array}$ \\
\hline $\begin{array}{l}\text { Pereira, } \\
\text { Zanetti - } \\
2009, \\
\text { Brasil. }\end{array}$ & $\begin{array}{l}\text { O estudo teve } \\
\text { como objetivo } \\
\text { o } \\
\text { levantamento } \\
\text { das } \\
\text { complicações } \\
\text { decorrentes da } \\
\text { terapia } \\
\text { intravenosa. }\end{array}$ & Pesquisa de campo. & $\begin{array}{l}\text { Os dados de maior } \\
\text { expressividade } \\
\text { obtidos foram: } \\
77,3 \% \text { das punções } \\
\text { foram realizadas } \\
\text { pelo auxiliar de } \\
\text { enfermagem; 68\% } \\
\text { não usaram luvas } \\
\text { durante } \\
\text { procedimento; } 60 \% \\
\text { das punções } \\
\text { tiveram cuidado de } \\
\text { enfermagem } \\
\text { insatisfatório; } 47 \% \\
\text { dos dispositivos } \\
\text { permaneceram "in } \\
\text { situ" de } 24 \text { a } 72 \\
\text { horas; dentre as }\end{array}$ & \begin{tabular}{lr}
\multicolumn{2}{c}{ Os dados sugerem } \\
a necessidade de \\
um aprimoramento \\
da equipe de \\
enfermagem \\
relacionado à \\
terapia \\
intravenosa.
\end{tabular} \\
\hline
\end{tabular}




\begin{tabular}{|c|c|c|c|c|}
\hline & & & $\begin{array}{l}\text { complicações, } 20 \% \\
\text { relacionaram-se } \\
\text { com infiltração, } \\
5,4 \% \text { infiltração e } \\
\text { hematoma e } 5,3 \% \\
\text { obstrução. }\end{array}$ & \\
\hline $\begin{array}{l}\text { Torres, } \\
\text { Andrade, } \\
\text { Santos- } \\
2015, \\
\text { Brasil. }\end{array}$ & $\begin{array}{l}\text { Avaliar o } \\
\text { desempenho } \\
\text { dos } \\
\text { profissionais } \\
\text { de } \\
\text { Enfermagem } \\
\text { na execução da } \\
\text { punção venosa } \\
\text { periférica. }\end{array}$ & $\begin{array}{l}\text { Esse estudo foi } \\
\text { realizado em um } \\
\text { hospital geral de } \\
\text { grande porte, do } \\
\text { interior do Estado } \\
\text { de São Paulo. }\end{array}$ & $\begin{array}{l}\text { Constou de } 55 \\
\text { profissionais de um } \\
\text { hospital geral de } \\
\text { grande porte. Para a } \\
\text { coleta dos } \\
\text { dados, foi utilizado } \\
\text { um instrumento de } \\
\text { observação do tipo } \\
\text { "check-list", } \\
\text { contendo } 25 \text { itens. }\end{array}$ & $\begin{array}{l}\text { Os dados apontam } \\
\text { a necessidade de } \\
\text { intensificar as } \\
\text { atividades } \\
\text { educativas } \\
\text { que promovam a } \\
\text { mudança } \\
\text { comportamento } \\
\text { dos profissionais } \\
\text { de enfermagem em } \\
\text { prol da qualidade. }\end{array}$ \\
\hline
\end{tabular}

Fonte: os autores (2020).

Foi constatado que a melhor prevenção para as complicações relacionadas ao acesso venoso está diretamente ligada à escolha de veias mais calibrosas, ou a utilização de acesso central para administração de soluções hipertônicas. Também é citada, a escolha do menor dispositivo indicado à infusão, com rodízio a cada 72 horas do local puncionado, fixação do dispositivo para prevenir irritação mecânica, punções realizadas por profissionais habilitados, lavagem das mãos adequadamente, protocolo de orientação sobre administração de medicamentos irritantes e soluções hipertônicas e troca dos frascos de soluções a cada 24 horas (Phillips, 2011).

\section{Discussão}

Garantir a segurança dos pacientes é fundamental para oferecer uma assistência de saúde e de enfermagem de qualidade. No entanto, se por um lado as intervenções de cuidados de saúde buscam melhorar a assistência prestada, por outro lado, a combinação de processos, tecnologias e recursos humanos relacionados com o cuidado à saúde pode se tornar um fator de risco para o surgimento de erros e complicações.

Dentre os muitos cuidados que o profissional de enfermagem executa na UTI, está a 
inserção do cateter venoso central (CVC), por conseguinte, os maiores índices de infecções da corrente sanguínea, mau posicionamento do cateter e pneumotórax, são complicações frequentes entre pacientes submetidos a esse procedimento (Oliveira, Bezerra \& Pereira, 2008).

O referido autor relata ainda que a escolha do cateter venoso central por ser uma tecnologia indispensável à sobrevivência dos pacientes internados em estado crítico nas UTIs torna-se indispensável à busca constante e aperfeiçoamento do conhecimento não somente sobre a inserção do cateter, bem como outros procedimentos que o profissional da enfermagem seja responsável para evitar futuras complicações (Oliveira, Bezerra \& Pereira, 2008).

Durante sua estadia na UTI, os pacientes são submetidos há muitos procedimentos, em sua maioria complexa e que podem trazer consigo uma gama de complicações. Dentre esses procedimentos está à inserção dos cateteres centrais de inserção periférica (PICC), que são amplamente utilizados em unidades de terapia intensiva quando os pacientes necessitam de uma linha venosa por tempo prolongado (Lourenço \& Kakehashi, 2013).

Dentre as complicações pela inserção do PICC estão: obstrução do cateter; flebite mecânica; migração; formação de trombos; sangramento; fratura do cateter; extravasamento; perfuração cardíaca ou do vaso; flebites infecciosas; infecção do sítio de inserção e infecção sanguínea. Assim, para se evitar essas complicações o profissional deve deter conhecimento técnico científico para escolher o melhor local para inserção, as técnicas corretas, manejo do cateter de forma higiênica, bem como sua retirada no intervalo de tempo adequado (Lourenço \& Kakehashi, 2013).

A obtenção do acesso venoso periférico é parte essencial do cuidado de enfermagem. Para a punção intravenosa periférica são empregados vários dispositivos. Para tal, a enfermagem deve conhecer as indicações e especificidades de cada material para uma escolha segura que reduzam riscos de infecção e complicações (Oliveira, Bezerra \& Pereira, 2008). A flebite é uma das complicações da punção periférica, definida como inflamação das células endoteliais da parede venosa por fatores mecânicos, químicos ou infecciosos (Lourenço \& Kakehashi, 2013).

Os sinais da flebite podem ser classificados segundo Infusion Nurses Society em escala que vai de um a quatro, segundo os sinais e sintomas apresentados pelo paciente (Oliveira, Bezerra, Pereira, 2008). Observa-se na literatura pediátrica, o predomínio de casos grau I, ou seja, aqueles em que os pacientes apresentam eritema, com ou sem dor local ou edema, sem endurecimento e cordão fibroso não palpável; grau II com os mesmos sintomas da flebite de grau I, porém com endurecimento local (Torres, Andrade \& Santos, 2015). A observação da punção é extremamente importante para prevenir as complicações. A terapia deve ser suspensa, 
caso o local de inserção apresentar sinais e sintomas característicos de complicações (Nome, 2016).

Por meio da realização de técnica asséptica, a flebite pode ser evitada durante a inserção do dispositivo venoso e adoção de material adequado e de tamanho apropriado para o calibre da veia, preferencialmente de pequeno calibre, flexível, com alta resistência a dobras, integridade estrutural, fácil inserção, baixa trombogenicidade e aderência bacteriana. Deve ser realizada higiene das mãos adequadamente, antes da realização do procedimento (Grivicich, Regner \& Rocha, 2008). É preciso rodiziar o local de punção na vigência de sinais clínicos de complicações e estabilizar e fixar o cateter evitando movimentos de "vai-e-vem" (Pereira \& Zanetti, 2009).

É classificado que $60 \%$ do cuidado de enfermagem dispensado a manutenção dos cateteres venosos como insatisfatório. Tal fato exige uma necessidade de atenção permanente da equipe de enfermagem, quanto aos critérios da punção venosa e quanto aos cuidados para a manutenção, evitando assim possíveis complicações (Écheli \& Busato, 2016). No mesmo sentido, a lavagem das mãos antes, e após os cuidados, observação de queixas e reações do paciente e orientação quanto aos cuidados pós-punção são em gerais insatisfatórias (Carvalho \& Cassiani, 2012).

Quando não tratada precocemente, a flebite pode adiar a alta hospitalar, gerando septicemia, estando comumente relacionada à má-técnica de assepsia ou contaminação do cateter durante a fabricação, estocagem ou utilização (Barria \& Santande, 2008).

\section{Conclusão}

A punção venosa periférica é o procedimento invasivo mais comum realizado pela equipe de enfermagem em UTI. Portanto, sua execução e conservação, segundo critérios de prevenção e tratamento de suas complicações, constituem parte importante da assistência de enfermagem, pois as punções venosas periféricas são sempre estressantes para o paciente, para família e para equipe de enfermagem.

Sendo assim, se faz necessário intensificar as atividades educativas que promovam a reflexão, atualização e a mudança de comportamento com vistas à qualidade do desempenho dos profissionais de saúde, principalmente, da equipe de enfermagem que executa o maior número de punções venosas periféricas em pacientes críticos. 


\section{Referências}

Barria, R. M., \& Santande, G. (2008) Acesso vascular periférico em neonatos de cuidado intensivo: experiência de um hospital público. Rev Saúd Public, 2(3), 35-44.

Carvalho, V. T., \& Cassiani, S. H. B. (2012) Erros na medicação e consequências para profissionais de enfermagem e clientes: um estudo exploratório. Rev. Bras. Enferm, 10(4), 523529.

Centers for Disease Control and Prevention (2015) Guidelines for the prevention of intravascular catheter related infections. Washington: DC: MMWR.

Écheli, C. S. B., \& Busato, C. R. (2016) Tratamento tópico de úlcera de estase venosa-proposta para padronização. Rev. Enferm UFPE, 12(1), 7-14.

Ferreira, L. R., Pedreira, M. L. G., \& Diccini, S. (2009) Flebite no pré e pós-operatório de pacientes neurocirúrgicos. Acta Paulist. de Enferm., 20(1), 30-36.

Grivicich, I., Regner, A., \& Rocha, A. B. (2008) Morte celular por apoptose. Ver Gaúch. Enferm., 53(3), 335-43.

Hamilton, H. (2008) Complication associated with venous access devices: part two. Nurs. Stand, 20(27), 59-65.

Intravenous Nurses Society (2012) Infusion nursing standards of practice. J. Intraven. Nurs., $3(65), 1-46$.

Lourenço, A. S., \& Kakehashi, T. Y. (2013) Avaliação da implantação do cateter venoso central de inserção periférica em neonatologia. Rev. Esc. Enferm. USP, 16(2), 26-32.

Nomi, C. (2016) Prevenção de infecção relacionada a cateter vascular: uma breve análise do guideline do CDC. Rev. Bras. Enferm, 6(4), 23. 
Oliveira, M. I. V., Bezerra, M. G. A., \& Pereira, V. R. (2008) Cateterização venosa: assistência de enfermagem -UTI Pediátrica. Rev. Enferm UFPE, 9(2), 90-7.

Pereira, R. C. C., \& Zanetti, M. L. (2009) Complicações decorrentes da terapia intravenosa em pacientes cirúrgicos. Rev. Bras. Enferm, 8(5), 21-7.

Phillips, L. D. (2011) Complicações da terapia intravenosa: Manual de terapia intravenosa. (2a ed). Porto Alegre: Artmed.

Torres, M. M., Andrade, D., \& Santos, C. B. (2015) Punção venosa periférica: avaliação de desempenho dos profissionais de enfermagem. Rev. Bras. Enferm, 13(3), 299-304.

Waitt, C., Waitt, P., \& Pirmohamed, M. (2014) Review: intravenous therapy. Postgrad Med J, $80,1-6$.

Webster, J., et al (2010) Clinically-indicated replacement versus routine replacement of peripheral venous catheters. Cochrane Database Syst Ver, 17(3).

\section{Porcentagem de contribuição de cada autor no manuscrito}

Marlise dos Santos Borges $-40 \%$

Jorge Luiz Lima da Silva - 10\%

Giulia Lemos de Almeida - 10\%

Lia Cristina Galvão dos Santos - 10\%

Lunna Machado Soares - 10\%

Vittória Thiengo Oliveira Moreira Rego - 10\%

João Victor Lima da Silva - 10\% 